\title{
EXPERIMENTAL VALIDATION OF A DYNAMIC MODEL FOR A RESIDENTIAL HEAT PUMP WITH IMMERSED CONDENSER
}

\author{
R. O. Nunes ${ }^{\mathrm{a}}$, \\ R. N. Fariab, \\ L. Machadoc, \\ R. Huebner ${ }^{c}$, \\ and R. N. N. Koury ${ }^{c}$ \\ ${ }^{a}$ Department of Mechanical and Aerospace \\ Engineering, Jacobs School of Engineering, \\ University of California San Diego. \\ 9500 Gilman Drive, La Jolla, CA 92093, USA \\ rphnunes@gmail.com \\ ${ }^{b}$ Centro Federal de Educação Tecnológica de \\ ABSTRACT \\ This work describes the validation of a dynamic model for a vapor \\ compression residential heat pump with an immersed condenser. A detailed \\ description of the modelling methodology for each component (compressor, \\ capillary tube, evaporator, and immersed condenser) and the solution \\ methodology employed in the complete heat pump system are presented. \\ The main contribution of this work is in the dynamic modeling of the \\ thermal processes occurring within the heat exchangers. Instabilities of the \\ solutions for the heat exchangers are minimized by considering spatially \\ and temporal varying errors. Another contribution of the model is the \\ investigation of the temperature distribution inside the water storage tank, \\ which highlights the possibility of using immersed condensers for this \\ purpose without significant thermal stratification in the tank. Simulation \\ results and experimental results are compared for transient operations using \\ multivariate profiles of temperature, pressure and mass flow rates in heat \\ exchangers during the water heating process.
}

Minas Gerais, Departamento de Engenharia

Mecatrônica

Avenida Álvares de Azevedo, 400

CEP 35503-822

Divinopólis, MG, Brasil

${ }^{c}$ Universidade Federal de Minas Gerais, Programa de Pós-graduação em Engenharia

Mecânica

Avenida Antônio Carlos Avenue, 6627

CEP 31270-901

Belo Horizonte, MG, Brasil

Received: January 12, 2015

Revised: February 23, 2015

Accepted: March 31, 2015

Keywords: heat pump, dynamic model, immersed condenser

\section{NOMENCLATURE}

A heat transfer area, $\mathrm{m}^{2}$

$\mathrm{D}$ tube diameter, $\mathrm{m}$

$f$ friction factor

$f_{L M} \quad$ Lockhart-Martinelli correction factor

G mass velocity

h specific enthalpy, $\mathrm{kJ} \mathrm{kg}^{-1}$

$\mathrm{H}$ heat transfer coefficient, $\mathrm{W} \mathrm{m}^{-2} \mathrm{~K}^{-1}$

$\mathrm{N}$ rotational speed, rpm

$\dot{\mathrm{m}}$ mass flow rate, $\mathrm{kg} \mathrm{s}^{-1}$

$\mathrm{p}$ perimeter, $\mathrm{m}$

$\mathrm{P}$ pressure, $\mathrm{Pa}$

$\Delta \mathrm{P}$ pressure drop, $\mathrm{Pa}$

$\mathrm{T}$ temperature, $\mathrm{K}$

$\mathrm{V}$ piston volumetric displacement, $\mathrm{m}^{3} \mathrm{~h}^{-1}$

$v \quad$ specific volume, $\mathrm{m}^{3} \mathrm{~kg}^{-1}$

\section{Greek symbols}

$\alpha \quad$ void fraction

$\eta \quad$ efficiency

$\rho \quad$ specific mass

$\omega$ humidity

\section{Subscripts}

1 input of the volume control

2 output of the volume control

a air

cond condensation

evap evaporation

f fluid refrigerant

1 liquid

lv liquid-vapor

pa specific heat at constant pressure

v vapor 


\section{INTRODUCTION}

The human being development is directly related to the types of energy that had access. It is virtually impossible to conceive of a nation socioeconomic development without a production and distribution of energy satisfactory. Residential water heating by electric showerheads is responsible approximately for $26 \%$ of the residential electric energy consumption in countries as Brazil, (https://ben.epe.gov.br, Web. 21 Dec. 2013) which creates a distortion on the electric demand load profile during the early evening hours, Martins (2008). Therefore alternatives for heating of residential water are capable of generating a large impact on the installed power capacity, reducing the energy demand at peak hours and helping to alleviate the overburden national power system. Here we consider heat pumps as low electricity consumption alternatives to direct Joule effect heating. Heat pumps use the energy available in ambient air for water heating and hence a significant reduction of electrical consumption is achieved in comparison with direct resistance electric showerheads, which are ubiquitous in Brazil.

In the present work, after a brief description about the experimental device, a dynamic model for a heat pump with immerse condenser is descripted. Numerical simulation of immerse condenser for stratification is also presented. Finally, numerical results are compared with experimental data.

\section{PREVIOUS WORK}

A critical problem in the development of discrete models for simulation and analysis of vapor compression systems is the sensitivity of the models to heating rates, which directly and nonlinearly affect the dynamic behavior of the system. In the case of evaporators and condensers these mechanisms show significant changes closely to the transition regions between two-phase and single-phase flow.

Discontinuity caused by the different correlations used to calculate, for example, the heat transfer coefficient, can lead to model instabilities which results in non-convergence. Recently, some authors presented a "moving boundary" method to minimize such instabilities, McKinley et al. (2008), Li and Alleyne (2009, 2010).

Models for vapor compression machines can be divided into two wide classes; models for steady state operation and models for transient regime of operation. These models can be used for studies on substitution of refrigerants, as well as the design and optimization of heating and cooling by vapor compression machines. The models for the transient regime of operation can be used for control purposes such as the control of the degree of super heat at the evaporator exit and in the study of the phenomenon resulting from changes in the operational conditions, among other application.

The literature shows many models working with the condenser water, however most of these uses countercurrent heat exchanger instead of immersed, considering that they have a better performance. Table 1 shows a brief summary of the models found in literature.

\section{DYNAMIC MODEL GENERAL DESCRIPTION}

The present model is designed to simulate the behavior of a heat pump in a transient regime operating with R-134a as refrigerant fluid for residential water heating. The following section describes the mains four heat pump component models (compressor model, capillary tube model, condenser model and evaporator model). For the condenser, a complementary study on thermal stratification is conducted through numerical simulations. The model results are validated by comparing the numerical predictions with experimental results.

\section{Compressor Model}

Before starting the calculations for the compressor, enumerated some hypothesis. The adiabatic compression process is irreversible, pressure losses in the suction and discharge valves are negligible, the mass flow rate is constant during compression, the refrigerant is pure, uncontaminated by the compressor oil. Koury et al. (2013) shows the following equation for calculating the mass flow of the compressor:

$$
\dot{m}_{\text {comp }}=\frac{N V \eta_{v}}{V_{\text {comp } 1}}
$$

where $\mathrm{N}$ is rotation, $\mathrm{V}$ is volume of the compressor, $\mathrm{v}_{\text {comp1 }}$ is specific volume of the fluid, and $\eta_{\mathrm{v}}$ is volumetric efficiency of the compressor. The latter was developed by multiple regressions to this specific compressor, Koury et al. (2013).

\section{Capillary Tube Model}

For the development of the mathematical model for the capillary tube are taken the following considerations. The capillary tube is straight and horizontal, one-dimensional flow inside the pipe, the expansion process is adiabatic, steady flow, no flow metastability regions, refrigerant considered pure and constant temperature in the single-phase region.

The model is made from the balance equations of energy, mass and momentum for fluid refrigerator in each of control volumes. Applying all the instances in general equations, can reach the following simplified equations: 


$$
\begin{gathered}
\frac{d h}{d z}=0 \\
\frac{d G}{d z}=0 \\
\frac{d p}{d z}=-\left(\frac{d p}{d z}\right)_{\text {atrito }}+\frac{d v}{d z}
\end{gathered}
$$

where $h$ is fluid enthalpy, $G$ is mass velocity, $f$ is friction factor, $\mathrm{v}$ is specific volume, $\mathrm{p}$ is pressure and $\mathrm{z}$ is direction of flow. In case of two-phase flow the Eq. (4) become depending of $\alpha$ (void fraction) and $x$ (quality), as it shown in the next equation:

$$
\frac{d p}{d z}=-\left(\frac{d p}{d z}\right)_{f}+\frac{d}{d z}\left[\frac{x^{2} \cdot v_{v}}{\alpha}+\frac{(1-x)^{2} \cdot v_{l}}{1-\alpha}\right]
$$

Also, there are localized losses at the entrance and exit of the capillary tube. The pressure loss caused by the entry of the fluid in the capillary tube is calculated according to the method of Maake et al. (1993). The pressure loss caused by the fluid outlet of the capillary tube is calculated according to the equation as suggested by Collier and Thome (1994).

For the single-phase region, the loss friction pressure is calculated using Churchill (1977) methodology, and for the two-phase region was used the methodology of Lockhart-Martinelli (1949).

Initially, the division is performed in small capillary control volumes. At the beginning of the capillary tube solves the equations for the pressure drop in-phase flow and the calculation of thermodynamic properties as proposed by Cleland (1986). This procedure is performed for each control volume. This procedure is repeated until the end of the capillary tube is reached. Towards the end of the capillary tube, it is found that the pressure calculated for the last exit control volume equals the pressure of evaporation. If so, the process ends. Otherwise corrects the input flow through the Newton Raphson algorithm.

For each flow rate tested, compares the speed of the fluid in the vapor phase with the corresponding speed of sound. If this exceeds the speed of sound, the flow is blocked. This situation is discussed in the work of García-Valladares (2007) and Kim et al. (2002). However, in this work, as the heat pump model is smaller, the mass flow of refrigerant in the system is low, so that critical flow was not observed during the heating of water.

\section{Heat Exchangers Model}

In order to heat exchangers model is necessary to consider few simplifying assumptions. These assumptions include considering the flow of refrigerant and air as one dimensional, in the two phase region the liquid and vapor are in thermodynamic equilibrium, no axial heat conduction and the radial temperature gradient along the tube wall is negligible, no heat loss to the ambient and, that the external heat transfer coefficient is uniform. In case of the evaporator one also considers that the heat transfer between the air and the adjacent control volumes is negligible. In the case of the condenser the water temperature is considered as the average bulk temperature in the tank. Based upon these assumptions it is possible to formulate the model as follows (the sub index $\mathrm{f}$ indicates the refrigerant and $\mathrm{w}$ indicates the wall).

$$
\begin{gathered}
A_{f} \frac{\partial}{\partial t}\left[\rho_{f}\left(h_{f}-P_{f} v_{f}\right)\right] \\
=-A_{f} \frac{\partial}{\partial z}\left(G_{f} h_{f}\right)+H_{f} p_{f}\left(T_{w}-T_{f}\right) \\
\frac{\partial \rho_{f}}{\partial t}+\frac{\partial G_{f}}{\partial z}=0 \\
\frac{\partial}{\partial z}\left\{P_{f}+G_{f}^{2}\left[\frac{x^{2} v_{v}}{\alpha}+\frac{(1-x)^{2} v_{l}}{1-\alpha}\right]\right\}=-\frac{\partial G_{f}}{\partial t}-\left(\frac{d P}{d z}\right)_{f}
\end{gathered}
$$

Above, a simplify form for mass, energy and momentum conservation for two-phase flow. The solution of these equations is done by choosing an arbitrary value for the saturation pressure. This allows solving the above equation for the $n$ control volumes of heat exchanger. If the mass flow rate at the exit to the heat exchanger is not equal to the mass flow rate delivered by the next device, then the saturation pressure must be corrected and the calculation procedure is repeated until convergence of the mass flow rate is achieved. To solve the equation of the refrigerant for each control volume, empirical equations are used to calculate the heat transfer coefficients, pressure loss and void fraction whether the flow regime is single or two phases. Having solved the equation of the refrigerant, it's necessary to solve the balance between the wall pipe and the fluid secondary. In this case, we build different balances for each heat exchanger.

\section{Evaporator}

The form for this heat pump water heater is the air-to-water system based on a standard fan-coil evaporator, which heat transfers in low pressure is done between the refrigerant and air ambient. For this heat exchanger the following equation shows the energy balance on the pipe wall and air.

$$
\begin{aligned}
& m_{w} c_{p w} \frac{\partial T_{w}}{\partial t} \\
& =H_{a}\left(A_{w}+\eta_{f i n} A_{f i n}\right) \cdot\left(T_{a}-T_{w}\right)-H_{f} A_{f}\left(T_{w}-T_{f}\right)+\sum_{i=1}^{4} Q_{i}
\end{aligned}
$$


Table 1. Literature vapor compression models.

\begin{tabular}{|c|c|c|c|c|c|c|}
\hline Paper & Subject & System & Validation & $\begin{array}{c}\text { Compressor } \\
\text { speed }\end{array}$ & Expansion Valve & $\begin{array}{c}\text { Heat } \\
\text { exchangers }\end{array}$ \\
\hline $\begin{array}{l}\text { McKinley et al. } \\
(2008)\end{array}$ & $\begin{array}{l}\text { Complete model of the vapor } \\
\text { compression cycle that included non- } \\
\text { circular tubes, fin effects, structure } \\
\text { thermal resistance, air temp nonlinear } \\
\text { distribution, upwind wall treatment for } \\
\text { rezoning and variable number of zones }\end{array}$ & Transient & No & Variable & $\begin{array}{c}\text { Thermostatic } \\
\text { expansion valve }\end{array}$ & $\begin{array}{c}\text { Air condenser } \\
\text { Water evaporator }\end{array}$ \\
\hline $\begin{array}{c}\mathrm{Li} \text { and Alleyne } \\
(2009,2010)\end{array}$ & $\begin{array}{l}\text { Model for a system of an air- } \\
\text { conditioning and refrigeration under } \\
\text { dynamic on/off operation with } \\
\text { switched moving boundary }\end{array}$ & Transient & Yes & Variable & $\begin{array}{l}\text { Thermostatic } \\
\text { expansion valve }\end{array}$ & $\begin{array}{l}\text { Air condenser } \\
\text { Air evaporator }\end{array}$ \\
\hline $\begin{array}{c}\text { Koury et al. } \\
\text { (2001) }\end{array}$ & $\begin{array}{l}\text { This work presents two numerical } \\
\text { models to simulate the unsteady and } \\
\text { steady state behavior of a vapor } \\
\text { compression refrigeration system. The } \\
\text { initial high and low pressure and } \\
\text { superheating degree must be guessed. }\end{array}$ & $\begin{array}{c}\text { Transient and } \\
\text { Steady }\end{array}$ & No & Variable & $\begin{array}{c}\text { Thermostatic } \\
\text { expansion valve }\end{array}$ & Not specificity \\
\hline $\begin{array}{l}\text { Kim et al. } \\
\text { (2002) }\end{array}$ & $\begin{array}{l}\text { Dynamic model for a water heater } \\
\text { driven by a heat pump system was } \\
\text { proposed. Compressor and the water } \\
\text { reservoir were modeled by lumped } \\
\text { systems. Heat exchangers are modeled } \\
\text { by finite volume elements and } \\
\text { expansion device is modeled to adjust } \\
\text { its opening for a designated superheat } \\
\text { at the compressor inlet. }\end{array}$ & Transient & No & Constant & $\begin{array}{l}\text { Thermostatic } \\
\text { expansion valve }\end{array}$ & $\begin{array}{l}\text { Water condenser } \\
\text { Air evaporator }\end{array}$ \\
\hline $\begin{array}{l}\text { Rigola et al. } \\
\text { (2006) }\end{array}$ & $\begin{array}{l}\text { The author presents a numerical and } \\
\text { experimental comparative study } \\
\text { between a conventional sub-critical } \\
\text { cycle and a carbon dioxide } \\
\text { transcritical refrigerating. }\end{array}$ & $\begin{array}{c}\text { Steady and } \\
\text { Transient }\end{array}$ & Yes & Constant & $\begin{array}{l}\text { Fixed opening } \\
\text { expansion valve }\end{array}$ & $\begin{array}{l}\text { Water condenser } \\
\text { Water evaporator }\end{array}$ \\
\hline $\begin{array}{c}\text { Winkler et al. } \\
\text { (2008) }\end{array}$ & $\begin{array}{l}\text { The work describes and investigates } \\
\text { the robustness and efficiency of three } \\
\text { unique algorithms used to simulate a } \\
\text { modular/component-based vapor } \\
\text { compression system. }\end{array}$ & Steady & No & Variable & $\begin{array}{c}\text { Thermostatic } \\
\text { expansion valve }\end{array}$ & Not specificity \\
\hline $\begin{array}{l}\text { Sarkar et al. } \\
(2006,2009)\end{array}$ & $\begin{array}{l}\text { In these two papers the authors present } \\
\text { mathematical models for a heat pump } \\
\text { cycle using } \mathrm{CO}_{2} \text { as refrigerant. The } \\
\text { results show a high system COP due } \\
\text { an efficient compression and good } \\
\text { transfers heat properties of the } \\
\text { refrigerant. }\end{array}$ & Steady & Yes & Constant & Not specified & $\begin{array}{l}\text { Water condenser } \\
\text { Water evaporator }\end{array}$ \\
\hline $\begin{array}{l}\text { Blanco et al. } \\
\text { (2012) }\end{array}$ & $\begin{array}{l}\text { It was presented a steady-state } \\
\text { simulation for a monovalent water-to- } \\
\text { water heat pump. The model works } \\
\text { with a constant superheating degree } \\
\text { control strategy and Initial } \\
\text { thermodynamic states of the cycle's } \\
\text { variables derived transparently from } \\
\text { inlet conditions. }\end{array}$ & Steady & Yes & Variable & $\begin{array}{l}\text { Controllable } \\
\text { opening electronic } \\
\text { expansion valve }\end{array}$ & $\begin{array}{l}\text { Water condenser } \\
\text { Water evaporator }\end{array}$ \\
\hline $\begin{array}{c}\text { Chamoun et al. } \\
\text { (2012) }\end{array}$ & $\begin{array}{l}\text { For this paper, the authors worked in a } \\
\text { mathematical model of a heat pump } \\
\text { using water as refrigerant. The great } \\
\text { advantage using water as refrigerant } \\
\text { was the possibility to have a heat } \\
\text { pump with high temperatures ranges. }\end{array}$ & Transient & No & Constant & $\begin{array}{c}\text { Thermostatic } \\
\text { expansion valve }\end{array}$ & $\begin{array}{l}\text { Water condenser } \\
\text { Water evaporator }\end{array}$ \\
\hline $\begin{array}{l}\text { Koury et al. } \\
\text { (2013) }\end{array}$ & $\begin{array}{c}\text { Dynamic model and experimental } \\
\text { study to simulate the performance of a } \\
\text { low cost heat pump for residential } \\
\text { water heating. }\end{array}$ & Transient & Yes & Constant & Capillary Tube & $\begin{array}{c}\text { Water condenser } \\
\text { Air evaporator }\end{array}$ \\
\hline $\begin{array}{l}\text { Zhao et al. } \\
\text { (2014) }\end{array}$ & $\begin{array}{l}\text { In this paper, a model-based } \\
\text { optimization strategy for vapor } \\
\text { compression refrigeration cycle was } \\
\text { developed, which was formulated as } \\
\text { minimizing the total operating cost of } \\
\text { the energy consuming devices subject } \\
\text { to the constraints of mechanical } \\
\text { limitations. component interactions, } \\
\text { environment conditions and cooling } \\
\text { load demands. }\end{array}$ & Transient & Yes & Constant & $\begin{array}{c}\text { Electronic } \\
\text { expansion valve }\end{array}$ & $\begin{array}{l}\text { Air condenser } \\
\text { Air evaporator }\end{array}$ \\
\hline $\begin{array}{c}\text { Nyers and Nyers } \\
\text { (2014) }\end{array}$ & $\begin{array}{l}\text { The authors have done a study of a } \\
\text { heat pump plate condenser } \\
\text { performance depending on external } \\
\text { impacts. The external impacts were } \\
\text { the inlet temperature of hot water, the } \\
\text { hydraulic resistance of the hot water } \\
\text { circuit, the power of circulation pump } \\
\text { and the surface of condenser. They } \\
\text { also found the appropriate power of } \\
\text { circulation pump to obtain the near } \\
\text { maximum condenser performance as a } \\
\text { function of resistance to flow in the } \\
\text { hot water circuit and dimension of } \\
\text { condenser. }\end{array}$ & Steady & Yes & Constant & Not specified & Water condenser \\
\hline
\end{tabular}


where $A_{f}$ is the cross section area for the refrigerant flow, $A_{w}$ is the external surface area of the tubes and $A_{\text {fin }}$ is area of the fins, respectively while the summation in $\mathrm{Q}$ represent the heat transferred by conduction from the fins of a control volume to another control volume.

The sum shows four parts due to each control volume be adjacent to four others and a plan. On the periphery of the heat exchanger, a control volume can be adjacent to two or three other control volumes, depending on location. Thus, in these cases, the sum has two or three terms. The effectiveness of the fin $\left(\eta_{\text {fin }}\right)$ is given by Wang and Touber (1991) and the heat coefficient for refrigerant $\left(\mathrm{H}_{\mathrm{f}}\right)$ and for air $\left(\mathrm{H}_{\mathrm{a}}\right)$ is given by Incropera (2011).

\section{Condenser}

The most common to the condenser is the countercurrent heat exchanger form. However for this work an immersed condenser was chosen, considering that this type of heat exchanger is more suited for a type of low cost heat pump. It consists of a heat exchanger composed of a copper tube, which flow a refrigerant, submerged in an insulated tank containing the water to be heated. The heat transfer occurs by natural convection. Figure 1 shows the immersed condenser details.

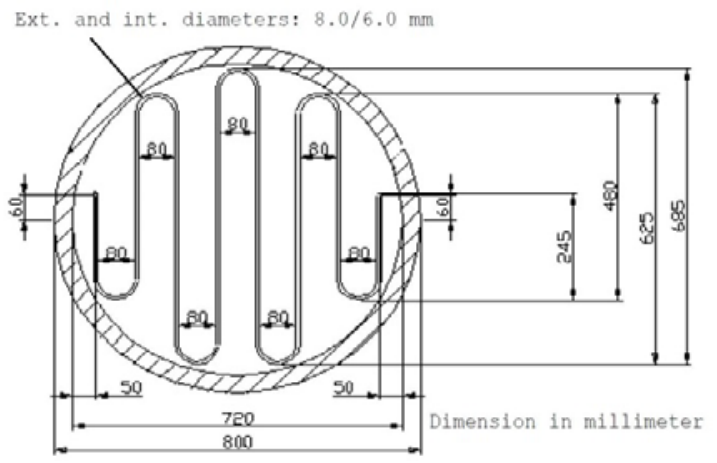

Figure 1. Immersed condenser details.

The calculation of the condenser wall temperature and temperature of the water in the tank is simpler than the case of the evaporator.

$$
\rho_{w} A_{w} c_{p w} \frac{\partial T_{w}}{\partial t}=H_{\text {water }} A_{w}\left(T_{\text {water }}-T_{w}\right)-H_{f} A_{f}\left(T_{w}-T_{f}\right)
$$

where the heat coefficient for water $\left(\mathrm{H}_{\text {water }}\right)$ is calculated based in Dittus-Boelter methodology, Incropera (2011).

One of the problems in immersed condenser use is a possible stratification of the water inside the tank, which would harm the process of heat exchange between the refrigerant and water. The following section shows a numerical simulation to investigate the stratification inside the tank.

\section{NUMERICAL INVESTIGATION FOR STRATIFICATION}

The heat transfer process in a condenser was simulated using computational fluid dynamics. It was assumed that the condenser has a cylindrical geometry; with a height of $1 \mathrm{~m}$, base diameter of $0.63 \mathrm{~m}$ and uses water as a heat exchange fluid. Water heating simulations were performed considering the condenser was filled to the level of $0.32 \mathrm{~m}, 0.64 \mathrm{~m}$ and $0.96 \mathrm{~m}$. The heat transfer process was simulated over 2 hours $(7200 \mathrm{~s})$ in accordance with the experiment. Based on experimental data, during the 4200s initials, it was considered a heat flux of 2100 $\mathrm{W} / \mathrm{m}^{2}$, applied uniformly over the entire base of the condenser. After 4200s the heat flux value was increased to $5800 \mathrm{~W} / \mathrm{m}^{2}$ and kept constant up to 7200s.

All other surfaces were considered adiabatic. The equations considered in the modeling were the mass conservation, momentum and energy, in nonstationary condition. The simulations were performed using the program Ansys CFX 12.1. The meshes were generated employing the Ansys Workbench. The convergence criterion adopted was the rms (root mean square of the normalized values) of 10-4. Mesh tests were carried out until the difference between the solutions, considering specific points inside the condenser, was less than $1^{\circ} \mathrm{C}$ at each point. The time step used was $1 \mathrm{~s}$. At each time step the set of equations could be solved up to 10 times. Initially the analysis will be made considering results for the level of $0.32 \mathrm{~m}$ by comparing numerical results with the experimental data.

Figure 2 shows the variation of temperature over time at points along the axis line of the condenser. The first point is located $5 \mathrm{~cm}$ from the base (bottom), the second at $16 \mathrm{~cm}$ from the base (middle) and the last $32 \mathrm{~cm}$ of the base (top). There is a good agreement between the numerical and experimental results, with a maximum difference of $7.87 \%$ for the point located $32 \mathrm{~cm}$ from the base (top), at time $45 \mathrm{~min}$. The curves show variation in the inclination from 70 minutes depending on the heat flux applied to the base of the condenser.

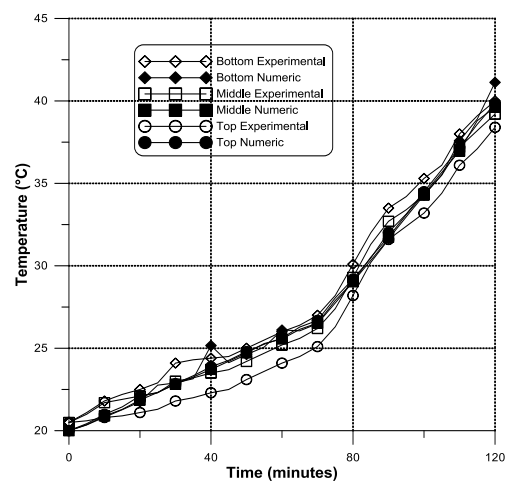

Figure 2. Temperature profiles, experimental and numerical over time - Level of $0.32 \mathrm{~m}$. 
Figure 3 shows the variation of the average temperatures, experimental and numerical over time. Means were calculated based on the temperatures of the three points considered. The bars indicate the dispersion (standard deviation) of the experimental results. There is good agreement between numerical and experimental results and the numerical results curve is within the range of dispersion of experimental results, validating the numerical model. The experimental highest standard deviation was $0.94^{\circ} \mathrm{C}$, for the time of 30 minutes. Considering the numerical results, the maximum standard deviation was $0.66^{\circ} \mathrm{C}$, for the time 120 minutes. The lowest dispersion obtained by simulation indicates a more uniform temperature distribution throughout the condenser. Experimentally, the largest temperature difference observed was $2.3^{\circ} \mathrm{C}$ for a time of 30 minutes, while numerically this value is $0.74^{\circ} \mathrm{C}$ for the time 120 minutes.

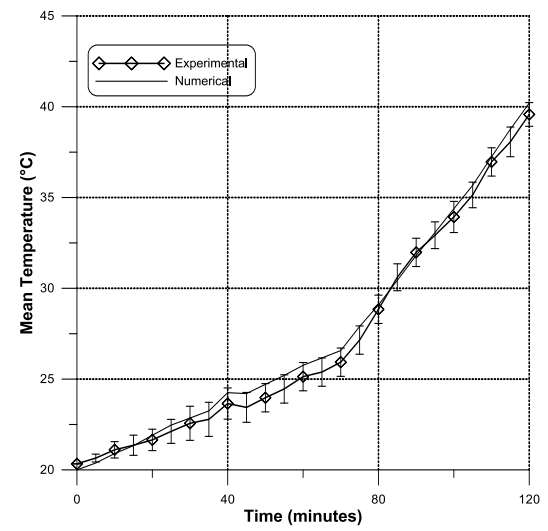

Figure 3. Average temperature profiles over time Level of $0.32 \mathrm{~m}$.

Figure 4 shows the numerical results for the three levels of water in the condenser. It is observed that the decrease of the water temperature is due to the increased volume of water inside the condenser. Note the variation in the slope of the curves depending on the boundary condition of heat flux, variable in time.

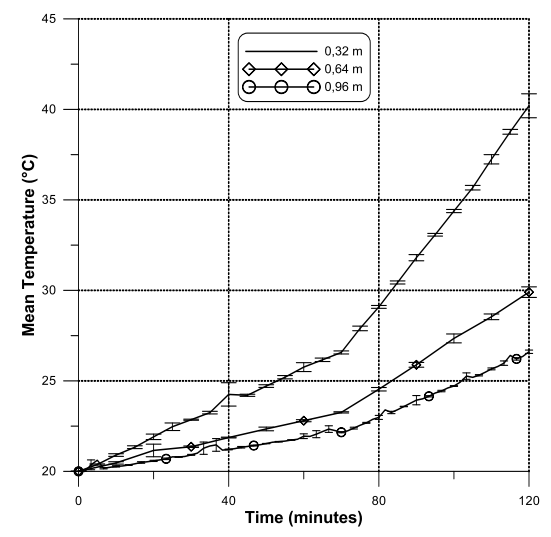

Figure 4. Average temperature profiles over time for all levels.
The curve shown for the water level $0.64 \mathrm{~m}$ represents the average of five points positioned along the axis line of the condenser. The heights considered were $5 \mathrm{~cm}, 16 \mathrm{~cm}, 32 \mathrm{~cm}, 48 \mathrm{~cm}$ and $64 \mathrm{~cm}$, from the condenser base. The maximum standard deviation observed was $0.68^{\circ} \mathrm{C}$ for the time 105 minutes. The maximum temperature difference was $1.64^{\circ} \mathrm{C}$ between the points of maximum and minimum dimension, at time 116 minutes. The curve representing the level $0.96 \mathrm{~m}$ is the average result from seven points along the centerline of the system. The heights considered were $5 \mathrm{~cm}, 16 \mathrm{~cm}, 32 \mathrm{~cm}$, $48 \mathrm{~cm}, 64 \mathrm{~cm}, 80 \mathrm{~cm}$ and $96 \mathrm{~cm}$ from the base of the condenser. At 32 minutes were obtained the maximum deviation of $0.55^{\circ} \mathrm{C}$ and a maximum temperature difference of $1.43^{\circ} \mathrm{C}$ between the points of maximum and minimum height.

The numerical results are consistent representing satisfactorily system behavior over time. The values of standard deviation obtained numerically indicate that there is no significant stratification along the condenser. The value of maximum temperature difference observed was $1.64^{\circ} \mathrm{C}$; less than the experimentally value of $2.3^{\circ} \mathrm{C}$.

\section{SOLUTION METHODOLOGY}

The equations shown above were implemented as separate subroutines for compressor, capillary tube, evaporator and condenser. They were combined to form the dynamic heat pump simulation. The boundary conditions for the condenser are the compressor mass flow rate, compressor discharge enthalpy and capillary tube mass flow rate. For the evaporator it is the mass flow rate in compressor and capillary tube and the outlet enthalpy in condenser.

The system of equations was solved in each time step, in which arbitrate values for the saturations pressures and the superheat degree. Thus, through the compressor model, calculate the fluid mass flow and outlet enthalpy in the compressor; these values are used as inlet conditions for condenser. Knowing the condenser inlet conditions and initial conditions over this element, it is possible to determine all of the condenser spatial profiles. Then the capillary tube model calculates the fluid mass flow. If the mass flow value imposed by the capillary tube doesn't converge to the value provided by the condenser model at its output, the condensing pressure is corrected by Newton Raphson method. This iterative process is repeated until convergence is within an acceptable error. Then, the model of the evaporator is triggered. For this, a spatial profile to the evaporator is determined. The conditions of the evaporator outlet allow the activation of the compressor model to calculate the fluid mass flow in of this component. If the mass flow value imposed by the compressor does not converge with the mass flow on evaporator outlet a similar condenser iterative process is repeated until obtaining the convergence. 
For both heater exchangers used $0.1 \%$ as an acceptable error. Finally, it is necessary to check whether the values of the evaporation pressure and superheat degree at the evaporator outlet are equal to the values used in the calculations the condenser. If not, checked the stability of these values, the whole procedure of calculating the model should be resumed. Achieved this last convergence goes up to the instant of time subsequent to the end of a predetermined time. Figure 5 shows the flowchart of the algorithm for calculating the machine model.

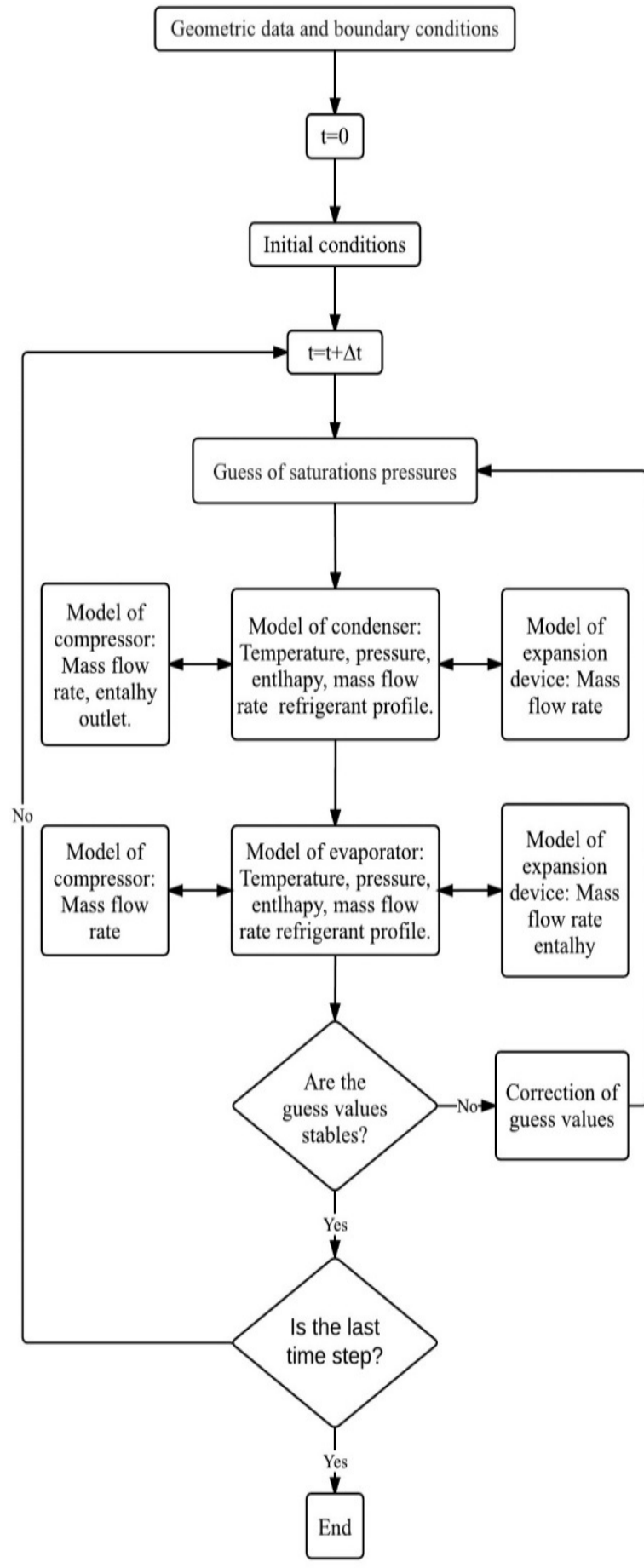

Figure 5. Heat pump model flowchart.

\section{RESULTS AND DISCUSSION}

This section presents the results obtained with the models developed in FORTRAN language for each of the main heat pump components. To develop the model of the complete machine, it is necessary that each model works perfectly when it works individually, as the data output of one device is used as input to the next device. Finally, after the presentation and review of the results obtained by each of these models, the results obtained with the model are completely validated through the comparison of model results with experimental data.

\section{Compressor Model Results}

The heat pump operates between the evaporation and condensation pressures, and hence between the differences of the compressor admission temperature and evaporation temperature, and suffer variations along the machine operation range. This is due to the fact that they are closely related to the reservoir water temperature and the cross flow of air at the evaporator. It is necessary that this model be able to accommodate these changes, and provides the compressor discharge mass flow and enthalpy values for different entry conditions, which may occur during a complete machine simulation. Table 2 presents the compressor model results for some typical conditions for working zone where the heat pump for residential water heating is typically operated.

Table 2. Numerical predictions from the compressor model.

\begin{tabular}{ccccc}
\hline \multicolumn{3}{c}{ Inlet Datas } & \multicolumn{2}{c}{ Outlet Datas } \\
$\begin{array}{c}\mathrm{P}_{\text {evap }} \\
(\mathrm{kPa})\end{array}$ & $\begin{array}{c}\mathrm{P}_{\text {cond }} \\
(\mathrm{kPa})\end{array}$ & $\begin{array}{c}\Delta \mathrm{T} \\
\left({ }^{\circ} \mathrm{C}\right)\end{array}$ & \multicolumn{2}{c}{$\dot{\mathrm{m}}_{\text {comp }}(\mathrm{kg} / \mathrm{h})$} \\
& & & Model & Experimental \\
\hline 489.43 & 888.36 & 10 & 49.45 & 48.34 \\
415.28 & 1018.89 & 7 & 40.45 & 39.59 \\
350.01 & 1161.71 & 8.5 & 31.55 & 28.34 \\
314.81 & 1318.58 & 5.5 & 26.74 & 24.23 \\
292.9 & 1490.2 & 7.5 & 22.62 & 18.55 \\
262.26 & 1677.3 & 6 & 17.86 & 15.87 \\
\hline
\end{tabular}

\section{Capillary Tube Model Results}

For modeling the capillary tube it is necessary to define a standard configuration and working conditions for the capillary tube during the simulation. These considerations include the condensing temperature and the degree of subcooling at the outlet of the condenser and evaporating temperature. These values are generated each time step by the models of the condenser and evaporator. The capillary has an internal diameter of $1.2 \mathrm{~mm}$ and a length of $0.08 \mathrm{~m}$ and the refrigerant fluid used is R134-a. The predicted pressure and temperature distributions along capillary tube are presented in Fig. 6. 

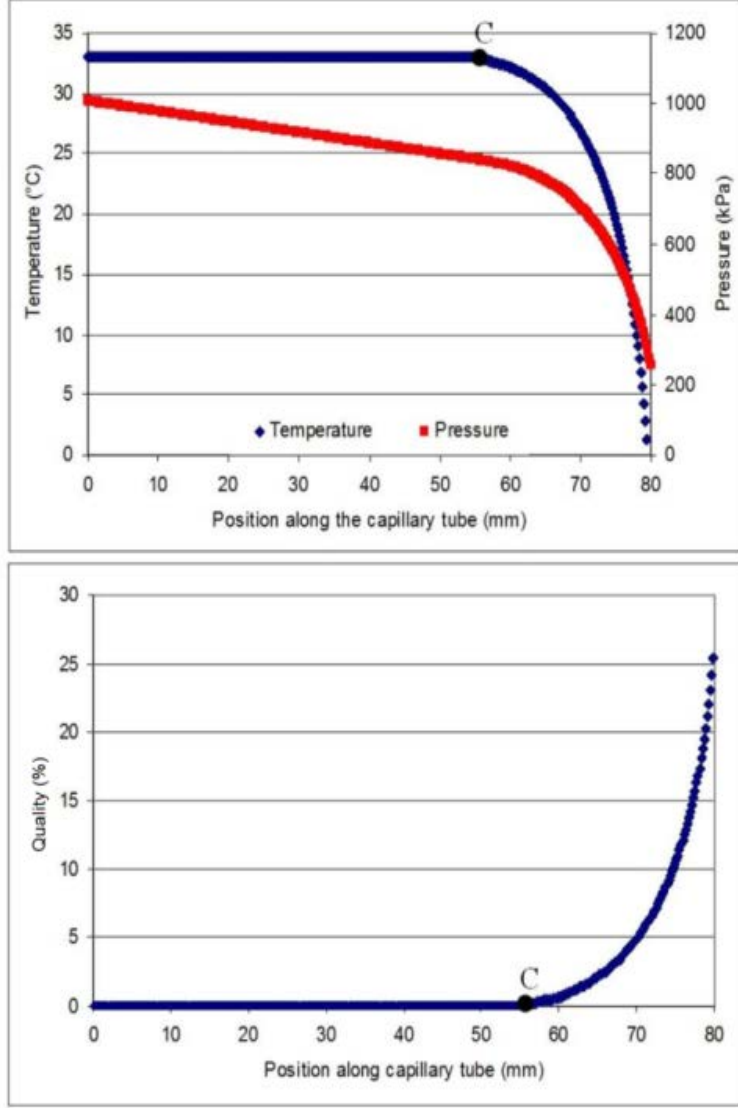

Figure 6. Temperature, pressure and quality profiles in capillary tube.

The fluid temperature along the capillary tube remains constant until the flow reaches the point $\mathrm{C}$, which marks the beginning of two-phase flow region and then falls rapidly. The initial pressure falls linearly in the one-phase flow region and starting from point $\mathrm{C}$, the pressure falls drastically towards the exit of the capillary tube. The title changes from zero for one phase flow, to more than $25 \%$ at the capillary tube exit.

\section{Evaporator Model Results}

Figure 7 shows the refrigerant, air and pipe wall temperatures along the evaporator length and the nearly constant fluid temperature occurs at about 3.5 $\mathrm{m}$ from the evaporator inlet indicates the evaporation zone. The temperature decrease in the two-phase flow region occurs due to the pressure drop considered during the refrigerant flow inside the evaporator.

The observed variations in the temperature profiles of the tube and air are due to the specific geometry of the evaporator, which is composed of a set of parallel rows of finned tubes. Hence it is possible that somewhere along the evaporator, the tube wall is cooled not only by the locally flowing refrigerant but also by a layer of already cold air cooled by another row of tube resulting in the variations shown.

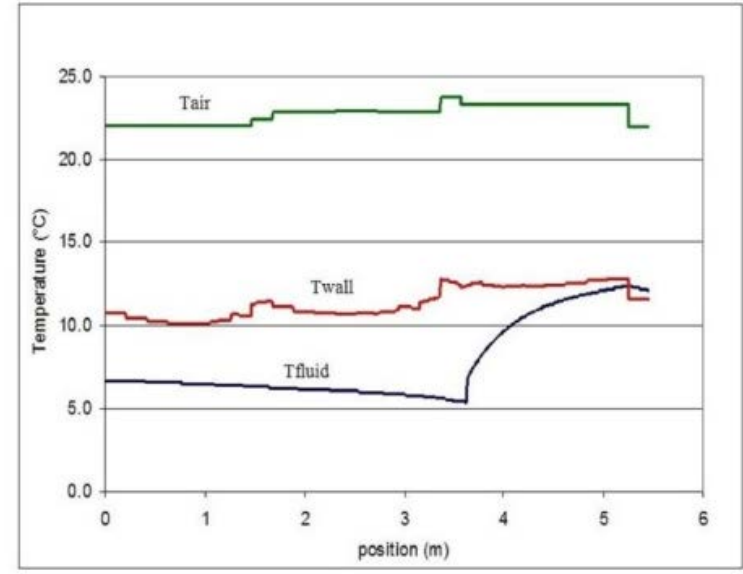

Figure 7. Fluid, pipe wall and air temperatures profiles in evaporator.

\section{Condenser Model Results}

Figure 8 presents the temperature evolution of the refrigerant, the tube wall and the heated water in the heat pump water tank for a time period more than $100 \mathrm{~s}$. The highest temperature of the refrigerant occurs at the compressor exit and decreases along the condenser until reaching the saturation temperature. From this point on phase change occurs. The condensation temperature decreases along the flow direction due to the pressure loss. The major part of the heat exchanger is used for condensing the refrigerant and only the small final part is used to provoke sub cooling as is expected.

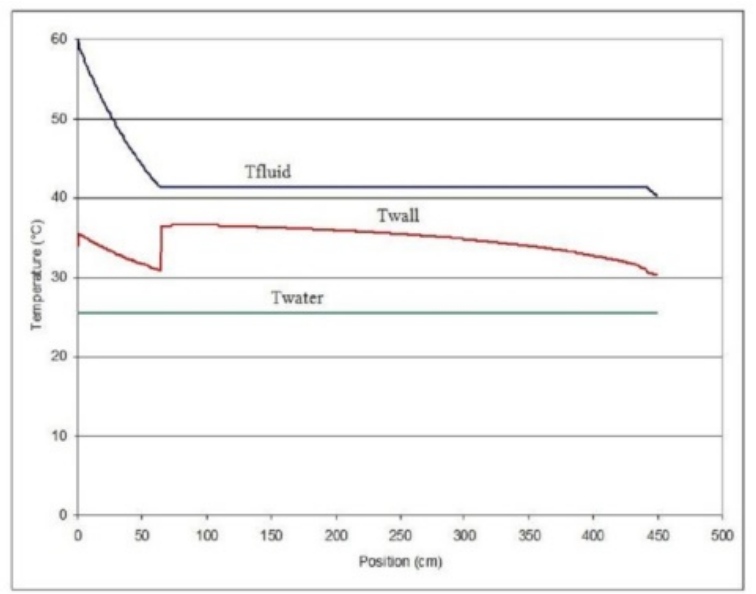

Figure 8. Variations of the fluid, pipe wall and water temperatures along condenser length.

\section{SYSTEM MODEL VALIDATION}

Figure 9 shows the temperature variations in the condenser, in the evaporator and in the water tank obtained both experimentally and from the numerical predictions. The tendencies are similar; however, the predicted water temperature changed more rapidly. 
The deviations between these results presented should not be attributed to uncertainties in experimental measurements, since all the thermocouples used in the tests were properly calibrated. The maximum combined uncertainty of the thermocouples and data acquisition system was \pm $0.3^{\circ} \mathrm{C}$.

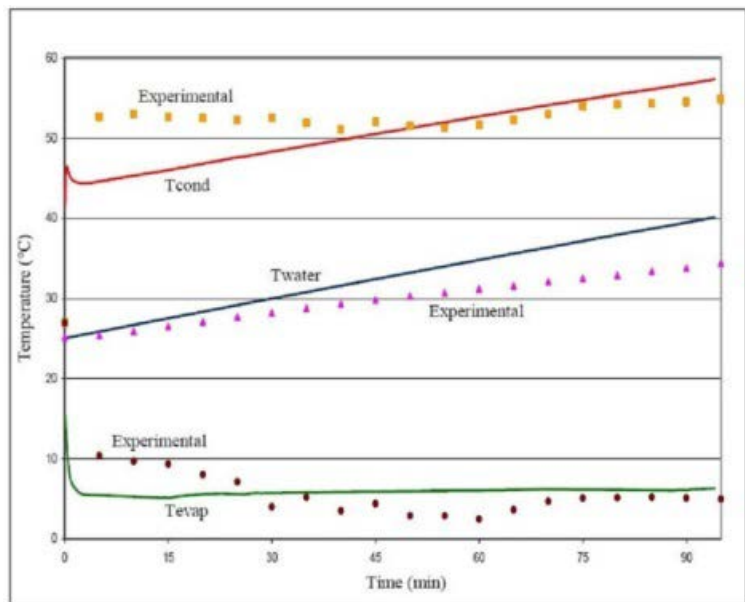

Figure 9. Variation of the temperature during the water heating process.

Figure 10 shows the thermodynamic cycle developed by the machine at certain instant both experimentally and numerically

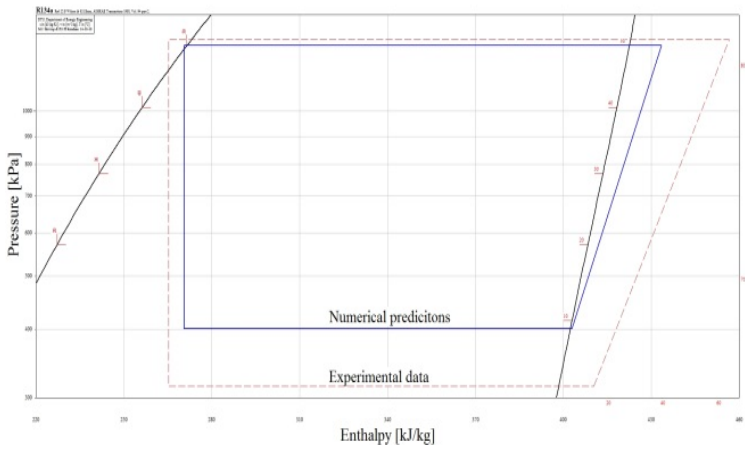

Figure 10. Thermodynamic cycle of experimental and model.

In case of the experimental cycle, the pressure loss in the heat exchangers was omitted due to difficulties encountered in its measurement.

From this figure, one can conclude that the compression work used for the numerical simulation is much smaller than the real compression work. This results in a higher COP and in less time for water heating.

In the experimental model there is some lubricating oil circulating together with the refrigerant in the condenser, which deteriorates the mechanisms of heat transfer to the water in the tank.

The degree of sub cooling in the condenser and superheating in the evaporator are considerably smaller in the model predictions, because in the calculations, the additional entry lengths were not included. A more elaborate model that takes these additional entry lengths into account is under development.

Figure 11 and 12 present maps of the evolution of the refrigerant fluid temperature along the lengths of the condenser and the evaporator, respectively. The model also permits predicting maps of the pressure, enthalpy, specific volume, and mass flow rate, quality and, void fraction as well as the maps of the wall and the secondary fluid temperatures. The curves only show the first instants of simulation, and the rest is omitted for more clarity.

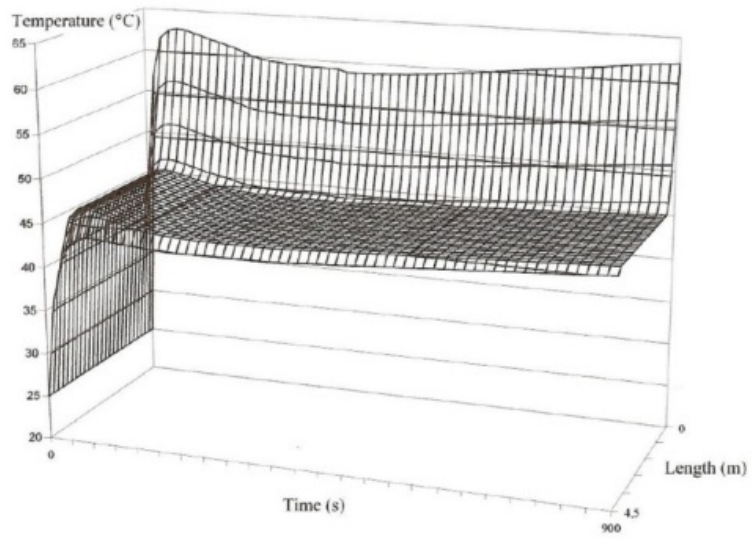

Figure 11. Refrigerant temperature along the condenser.

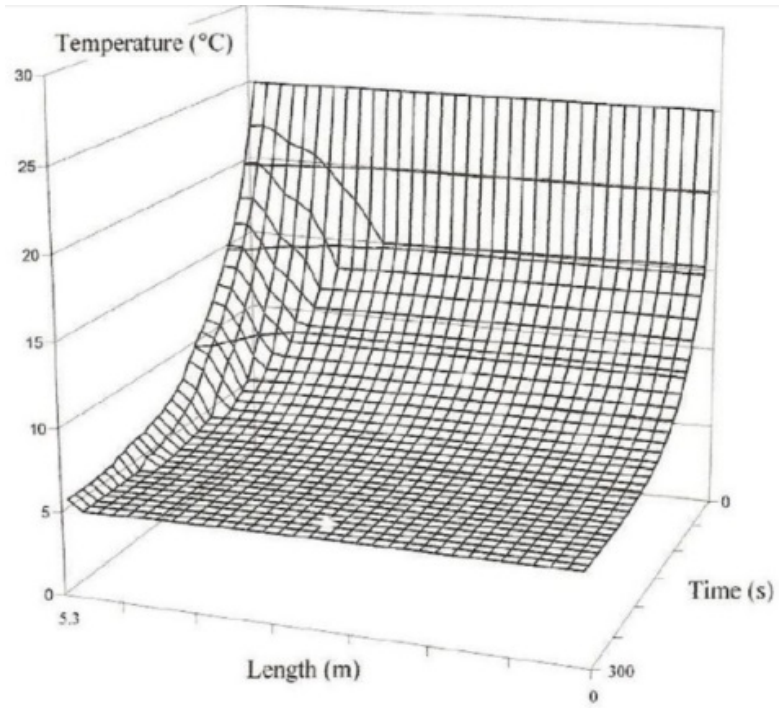

Figure 12. Refrigerant temperature along the evaporator.

\section{CONCLUDING REMARKS}

This work presents a numerical model to simulate the performance of a low cost heat pump for residential water heating. The model is based on 
simplified solutions of the coupled equations of conservation of mass, energy, and momentum that model the behavior of the main system components, i.e., compressor, capillary tube, condenser and evaporator. The numerical predictions from the components models are obtained and compared with the experimental results showing reasonably good agreement. Simulations with the complete model of the heat pump system composed of all of the components models showed reasonably good agreement with the experiments. The differences between the model predictions and the experimental measurements can be attributed mainly to the differences between the real system and the simulated one. For example, the refrigerant circulating in the heat pump system is considered pure in the numerical simulations, while in the real system it is mixed with the lubrication oil and this impairs the condenser performance and consequently water heating. In additional, the immersed condenser appears as a good option as the heat exchanger, showing no great stratification.

\section{REFERENCES}

Blanco, D. L., Katsunori N., and Masahiro M., 2012, Steady State Vapor Compression Refrigeration Cycle Simulation for a Monovalent Inverter-Driven Water-to-Water Heat Pump with a Desuperheater for Low Energy Houses, International Journal of Refrigeration, Vol. 35, No. 7, pp. 1833-1847.

Chamoun, M., Rulliere, R., Haberschill, P., and Berail, J. F., 2012, Dynamic Model of an Industrial Heat Pump using Water as Refrigerant, International Journal of Refrigeration, Vol. 35, No. 4, pp. 10801091.

Churchill, S. W., 1997, Friction-Factor Equation Spans all Fluid-Flow Regimes, Chemical Engineering, Vol. 84, No. 24, pp. 91-92.

Cleland, A. C., 1986, Computer Subroutines for Rapid Evaluation of Refrigerant Thermodynamic Properties, International Journal of Refrigeration, Vol. 9, No. 6, pp. 346-351.

Collier, J. G., and John, R. T., 1994, Convective Boiling and Condensation, Oxford University Press.

García-Valladares, O., 2007, Numerical Simulation and Experimental Validation of Coiled Adiabatic Capillary Tubes, Applied Thermal Engineering, Vol. 27, No. 5, pp. 1062-1071.

Incropera, F. P., 2011, Fundamentals of Heat and Mass Transfer, John Wiley \& Sons.

Kim, S. G., Kim, M. S., and Ro, S. T., 2002, Experimental Investigation of the Performance of R22, R407C and R410A in Several Capillary Tubes for Air-conditioners, International Journal of Refrigeration, Vol. 25, No. 5, pp. 521-531.

Koury, R. N. N., Faria, R. N., Nunes, R. O., Ismail, K. A. R., and Machado, L., 2013, Dynamic Model and Experimental Study of an Air-Water Heat Pump for Residential Use, International Journal of
Refrigeration, Vol. 36, No. 3, pp. 674-688.

Koury, R. N. N., Machado, L., and Ismail, K. A. R., 2001, Numerical Simulation of a Variable Speed Refrigeration System, International Journal of Refrigeration, Vol 24, No. 2, pp. 192-200.

Li, B., and Alleyne, A. G., 2009, A Full Dynamic Model of a HVAC Vapor Compression Cycle Interacting with a Dynamic Environment, in: American Control Conference, ACC'09, pp. 36623668.

Li, B., and Alleyne, A. G., 2010, A Dynamic Model of a Vapor Compression Cycle with ShutDown and Start-Up Operations, International Journal of Refrigeration, Vol. 33, No. 3, pp. 538-552.

Lockhart, R. W., and Martinelli, R. C., 1949, Proposed Correlation of Data for Isothermal TwoPhase Two-Component Flow in Pipes, Chemical Engineering Progress, Vol. 45, No. 1, pp. 39-48.

Maake, W., Eckert, H. J., Cauchepin, J. L., and Le Pohlmann., 1993, Manuel Technique du Froid, PYC Edition

Martins, F. R., Pereira, E. B., Silva, S. A. B., Abreu, S. L., and Colle, S., 2008, Solar Energy Scenarios in Brazil, Part one: Resource Assessment, Energy Policy, Vol. 36, No. 8, pp. 2853-2864.

McKinley, T. L., and Alleyne, A. G., 2008, An Advanced Nonlinear Switched Heat Exchanger Model for Vapor Compression Cycles Using the Moving-Boundary Method, International Journal of Refrigeration, Vol 31, No. 7, pp. 1253-1264.

Nyers, J., and Nyers, A., 2014, Investigation of Heat Pump Condenser Performance in Heating Process of Buildings Using a Steady-State Mathematical Model, Energy and Buildings, Vol. 75, No.1, pp. 523-530.

Rigola, J., Raush, G., Perez-Segarra, C. D., and Oliva, A., 2006, Numerical Analysis and Experimental Validation of Transcritical Carbon Dioxide Cycles for Small Cooling Capacities. Hermetic and Semi-Hermetic $\mathrm{CO}_{2}$ Reciprocating Compressor Comparison, in: 7th IIR Gustav Lorentzen Conference on Natural Working Fluids, Trondheim, Norway, pp. 454-458.

Sarkar, J., Bhattacharyya, S., and Ramgopal, M., 2006, Simulation of a Transcritical $\mathrm{CO}_{2}$ Heat Pump Cycle for Simultaneous Cooling and Heating Applications, International Journal of Refrigeration, Vol. 29, No. 5, pp. 735-743.

Sarkar, J., Bhattacharyya, S., and Ramgopal, M., 2009, A Transcritical $\mathrm{CO}_{2}$ Heat Pump for Simultaneous Water Cooling and Heating: Test Results and Model Validation, International Journal of Energy Research, Vol. 33, No. 1, pp. 100-109.

Wang, H., and Touber, S., 1991, Distributed and Non-Steady-State Modelling of an Air Cooler, International Journal of Refrigeration, Vol. 14, No. 2, pp. 98-111.

Winkler, J., Aute, V., and Radermacher, R., 2008, Comprehensive Investigation of Numerical Methods in Simulating a Steady-State Vapor 
Compression System, International Journal of Refrigeration, Vol. 31, No. 5, pp. 930-942.

Zhao, P. C., Ding, G. L., Zhang, C. L., and Zhao, L., 2003, Simulation of a Geothermal Heat Pump with Non-Azeotropic Mixture, Applied Thermal Engineering, Vol. 23, No. 12, pp. 1515-1524. 